\title{
Unknown Primary Tumor pN2 TNM Finding v8
}

National Cancer Institute

\section{Source}

National Cancer Institute. Unknown Primary Tumor pN2 TNM Finding v8. NCI

Thesaurus. Code C132669.

Unknown primary tumor with metastasis in a single ipsilateral or contralateral cervical lymph node $3 \mathrm{~cm}$ or smaller in greatest dimension and $\mathrm{ENE}(+)$; or metastasis in a single ipsilateral cervical lymph node larger than $3 \mathrm{~cm}$ but not larger than $6 \mathrm{~cm}$ in greatest dimension and ENE(-); or metastases in multiple ipsilateral cervical lymph nodes, none larger than $6 \mathrm{~cm}$ in greatest dimension and $\mathrm{ENE}(-)$; or metastases in bilateral or contralateral cervical lymph nodes, none larger than $6 \mathrm{~cm}$ in greatest dimension and ENE(-). ENE detected on histopathologic examination is designated as ENEmi (microscopic ENE equal or less than $2 \mathrm{~mm}$ ) or ENEma (major ENE more than $2 \mathrm{~mm}$ ). (from AJCC 8th Ed.) 